\title{
A Study on Synthesis and Testing of Polyols Using Soybean Oil and Gastor Oil
}

\author{
Shahzad Maqsood Khan *,1 \\ Nafisa Gull ${ }^{1}$ \\ Muhammad Yaseen Akram ${ }^{2}$ \\ Hakim Ali Haider ${ }^{2}$ \\ Muhammad Yasir Akram ${ }^{2}$ \\ Muhammad Imran ${ }^{2}$ \\ Muhammad Taqi Zahid Butt ${ }^{3}$ \\ Tahir Jamil ${ }^{1}$ \\ ${ }^{1}$ Department of Polymer Engineering \& Technology, University of the Punjab, 54590, Lahore, \\ Pakistan \\ ${ }^{2}$ Institute of Chemical Engineering \& Technology, University of the Punjab, 54590, Lahore, \\ Pakistan \\ ${ }^{3}$ College of Engineering and Emerging Technologies, University of the Punjab, 54590, Lahore, \\ Pakistan \\ *e-mail : shahzad.pet.ceet@pu.edu.pk
}

The feasibility of methods of trans-esterification reactions for the preparation of polyols from unsaturated soybean oil and castor oil have shown in this study. The polyol products formed from soybean oil has primary alcohol functional group. For castor oil polyol, hydroxyl group of any chain of triglyceride is replaced by chlorine. Thus the polyol formed has two hydroxyl $(-\mathrm{OH})$ groups. Polyol is identified from hydroxyl functional group using Fourier Transform Infrared Spectroscopy (FTIR), and characterized by acid value. It is seen that the synthesized polyols are useful in the treatment of processes, using polyols for the production of polyurethanes, and also manipulated to synthesize polyurethane with required properties.

Keywords: Polyol, Soybean polyol, Castor oil, FTIR

\section{INTRODUCTION}

Vegetable oils are one of the most bountiful biological sources because of their several advantages: intrinsic biodegradability, low toxicity, and high purity (Stefan, 2010). Vegetable oils are extracted principally from the seeds of a variety of plants. Their worldwide availability, competitive cost, and built-in functionality make them striking (Maxime, 2012, Myriam, 2011). Transformation of vegetable oils and other natural products to polyols has opened up a new horizon and is a very promising area for new developments, such as: genetic 
engineering to create new triglycerides containing hydroxyl groups, synthesis of new polyols by selective oxidation of vegetable oils (for example microbial oxidation), new reactions for the transformation of double bonds in polyols such as ozonolysis-reduction, oxygenation reactions with molecular oxygen using special complex catalysts (nickel complexes such as nickel acetylacetonates), enzymic reactions, direct hydroxylation reactions with heterogeneous catalysts (titanium silicalite) and so on. Polyether and polyester polyol consumption from 2000 to 2004 is shown in figure 1.

The polyols used for the synthesis of urethane foam are the liquid oligomers having minimum two hydroxyl groups. Hydroxyl-terminated polyolefins, Polyester polyols, Polyether polyols and hydroxylcontaining vegetable oils are some examples of polyols (Ashida, 2007). Polyurethanes are obtained between the reaction of an oligomeric polyol and a diisocyanate or polyisocyanate.

Polyols used in polyurethane manufacture, from the structural point of view, are divided in two groups. The first group consist of of low molecular weight (MW) polyols, having unitary and concrete molecular weight and second group of low molecular weight polymers (oligomers with a maximum MW of 10,000 daltons) with terminal hydroxyl groups (hydroxy telechelic oligomers), called oligopolyols . In 1849 first urethane was synthesized by Wurtz using the following route (Lonescu, 2005).

$\mathrm{R}-\mathrm{N}=\mathrm{C}=\mathrm{O}+\mathrm{OH}-\mathrm{R}^{\prime} \rightarrow \mathrm{R}-\mathrm{NHCOO}-\mathrm{R}^{\prime}(1)$

Dr Otto Bayer of IG Farbenindustrie Germany synthesized first polyurethane in 1937. He reacted diisocyanate with polyester having hydroxyl groups which is called polyester diol to produce polyurethane (Bayer, 1947a, Bayer, 1947b). Since the existence of polyurethanes from 65 years there is a constant growth in the production and use of polyurethane. Future forecast is also very positive as fresh markets in Eastern Europe, Asia and South America (Detroit., 1998).

Raw materials for the production of

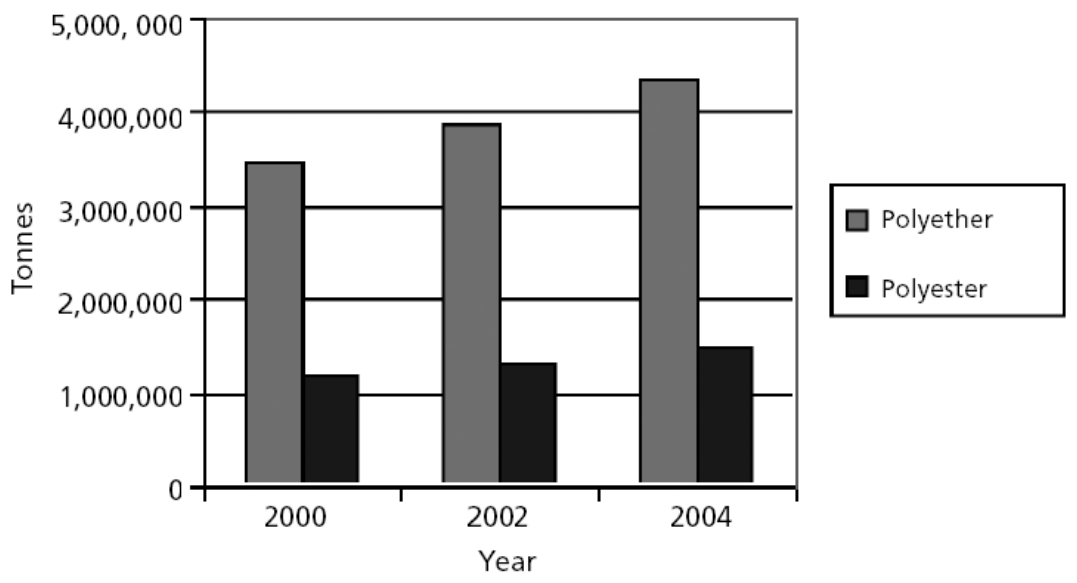

Fig.1: Polyether and polyester polyols consumption from 2000-2004 
Shahzad Maqsood Khan, Nafisa Gull, Muhammad Yaseen Akram, Hakim Ali Haider, 29 Muhammad Yasir Akram, Muhammad Imran, Muhammad Taqi Zahid Butt and Tahir Jamil

polyols are petro based and agro based.

Polymeric materials, such as polyurethane are in general derived from petro chemical polyols but now a day's production of polyols from petrochemicals involves heaps of energy and cost due to drilling and extraction of oil, transportation to refineries, refining and processing to yield appropriate polyols. In addition, these processes adversely affect the environment. Also due to high oil prices, and depletion of oil reservoir it is required to develop some substitute of petroleum base polyols to other more adaptable, renewable, economic and environmental friendly bio based polyol (Guo, 2002, Khoe, 1972, Phuong, 2005, Suresh, 2007, Szycher, 1999, Xiaohua, 2013). Worldwide economic and scientific interest in vegetable oils like soybean, linseed, sunflower, safflower, corn, canola etc. and fish oil, to be used for polyol production as a cost-effective, readily available renewable resource is rising day by day (Jhon, 2002, Mihail, 2007). Multiple hydroxyl functionality is prime requisite to utilize natural oils for polyurethane production. Hydroxyl group transpire in natural oils, such as castor oil. Double bond epoxidation followed by ring opening with alcohols, amino alcohols or acids is used to encapsulate hydroxyl functional group in soybean and linseed oil (Guo, 2000, Simone, 2007). Soybean is a rich source which is used to produce polyesters and polyurethanes. It depends on the fact that alcohol groups should be correctly tailored in its structure (Phuong, 2005).

Our aim of study was to synthesize polyol by using soybean oil and castor oil and then characterize them by different chemical and analytical techniques.

\section{EXPERIMENTAL}

\section{Materials}

All the chemicals used in the experiments, including Soybean Oil, Castor Oil, Potassium Hydroxide $(\mathrm{KOH})$, Ethyl Alcohol $\left(\mathrm{C}_{2} \mathrm{H}_{5} \mathrm{OH}\right)$, Hydrochloric Acid $(\mathrm{HCl})$, Iodine Mono-Chloride (Wij's solution; ICl), Carbon Tetrachloride $\left(\mathrm{CCl}_{4}\right)$, Sodium Thiosulfate $\quad\left(\mathrm{Na}_{2} \mathrm{~S}_{2} \mathrm{O}_{3} .5 \mathrm{H}_{2} \mathrm{O}\right)$, Starch Solution, Phenolphthalein, Potassium Iodide (KI), Sorbitol $\left(\mathrm{C}_{6} \mathrm{H}_{14} \mathrm{O}_{5}\right)$, Chloroform $\left(\mathrm{CHCl}_{3}\right)$ and Methylene diphenyl diisocyanate $\mathrm{C}_{15} \mathrm{H}_{10} \mathrm{~N}_{2} \mathrm{O}_{2}$ (MDI) were purchased locally, analytically pure and are used without any pre-treatment.

\section{Testing of raw materials}

Raw materials which have been subjected to testing are castor oil and soybean oil. Oils were first characterized for determining saponification number for molecular weight determination, Iodine number for the presence of double bonds and FTIR for functional group analysis.

\section{Saponification value test}

Alkali required for saponification of known amount of the material, is the determination of its saponification value. It is articulated as amount of potassium hydroxide $(\mathrm{KOH})$ in milligrams which is essential for saponification of one gram of testing material. This test is used for the calculation of molecular weight was performed according to ASTM D464 test method. According to which, $0.5 \mathrm{~N}$ Hydrochloric Acid was accurately standardized. Alcoholic potassium hydroxide $(\mathrm{KOH})$ was prepared by taking 5 to $10 \mathrm{~g}$ of reagent grade $\mathrm{KOH}$ pellets in a 2 liter flask. $95 \%$ ethyl alcohol (1-1.5 liter) 
was added in flask. It was boiled on water bath for 30 to 60 min under total reflux. Distilled alcohol was collected in a glass stopperd receiver. Low carbonate $40 \mathrm{~g}$ potassium hydroxide was dissolved in 1 liter distilled alcohol with cooling to keep the temperature at or below $15^{\circ} \mathrm{C}$ yielding a clear solution. $1.0 \%$ Phenolphthalein solution in $95 \%$ ethyl alcohol was also prepared. Oil samples were heated up to $100{ }^{\circ} \mathrm{C}$ until they turned into liquid and then mixed thoroughly. $2.00 \pm 0.10 \mathrm{~g}$ of oil was taken in a flask and $30.00 \mathrm{ml}$ of the alcoholic $\mathrm{KOH}$ (already prepared) was added in it. $30 \mathrm{ml}$ of $\mathrm{KOH}$ was taken in another flask. Both flasks were fitted with condensers and heated for 30-45 minutes and then cooled to room temperature resulting in formation of soap. Contents of each flask were titrated against $0.5 \mathrm{~N} \mathrm{HCl}$ and their volume was noted.

\section{lodine value test}

Iodine value test is used for the determination of unsaturation of the soybean oil. Number of grams of iodine that would add to carbon-carbon double bounds $(C=C)$ present in 100 grams of oil or fat is the Iodine number of that compound. ASTM D5768-02 (2006) was used to find iodine value of tall oil fatty acids. As per ASTM D5768-02 two flasks were taken and marked as $A$ and B. 0.100.50 grams of oil was added in flask $A$. In both flasks $10 \mathrm{ml}$ of carbon tetrachloride and $10 \mathrm{ml}$ of solution of iodine monochloride (ICl) was added. Both flasks were stopperd and were placed in dark for at least one hour. During that time period iodine mono chloride attacked the double bond present in the oil's fatty acid chain present in flask A. After one hour flask B was taken out and 3-4 grams of solid potassium iodide (KI) was added in it. Flask $B$ was titrated against $0.1 \mathrm{~N} \mathrm{Na} \mathrm{S}_{2} \mathrm{O}_{3} .5 \mathrm{H}_{2} \mathrm{O}$ till straw yellow color was obtained from reddish brown. 1-2 $\mathrm{ml}$ of starch solution was added in it to be used as an indicator. On adding starch solution, a complex of starch and iodine was formed having blue color. Titration was continued with $0.1 \mathrm{~N}$ $\mathrm{Na}_{2} \mathrm{~S}_{2} \mathrm{O}_{3} .5 \mathrm{H}_{2} \mathrm{O}$ till blue color was discharged. Noted the total volume of $0.1 \mathrm{~N}$ $\mathrm{Na}_{2} \mathrm{~S}_{2} \mathrm{O}_{3} \cdot 5 \mathrm{H}_{2} \mathrm{O}$ used. Repeated the same procedure for the contents in flask $\mathrm{A}$ and quantity of $0.1 \mathrm{~N} \mathrm{Na} \mathrm{S}_{2} \mathrm{O}_{3} .5 \mathrm{H}_{2} \mathrm{O}$ consumed after the addition of starch solution was noted.

\section{Functional groups Identification}

Functional groups were identified using IR Prestige Fourier Transform Infra Red Spectrophotometer (FTIR) Shimadzu Japan using 64 scans. Castor and soy bean oil was dissolved in chloroform separately. One drop of the solution was poured on Potassium Bromide $(\mathrm{KBr})$ crystals of Attenuated Total Reflectance (ATR) accessory. The solvent was evaporated after some time which results the formation of a thin layer of film on the crystal surface which was analyzed for functional group determination.

\section{Soybean based polyol synthesis}

Polyol was synthesized using soybean oil and sorbitol using potassium hydroxide $(\mathrm{KOH})$ as a reagent. This method involves the esterification and trans-esterification process. A two neck flask was charged with soybean oil, sorbitol and $\mathrm{KOH}$, fitted with a condenser and thermometer. The flask was placed in the rotamental at constant heating of about $185-190{ }^{\circ} \mathrm{C}$ for two hours 
Shahzad Maqsood Khan, Nafisa Gull, Muhammad Yaseen Akram, Hakim Ali Haider, 31 Muhammad Yasir Akram, Muhammad Imran, Muhammad Taqi Zahid Butt and Tahir Jamil

Table 1. Formulations of soybean oil based polyol

\begin{tabular}{cccccc}
\hline Sr. No. & $\begin{array}{c}\text { Soybean } \\
\text { Oil }(\mathrm{gm})\end{array}$ & $\begin{array}{c}\text { Sorbitol } \\
(\mathrm{gm})\end{array}$ & $\mathrm{KOH}(\mathrm{gm})$ & $\begin{array}{c}\text { Temperature } \\
\left({ }^{\circ} \mathrm{C}\right)\end{array}$ & Time (hrs) \\
\hline B1 & 200.4 & 20.05 & 6.06 & 190 & 2 \\
\hline B2 & 100.2 & 7.8 & 2.6 & 190 & 2 \\
\hline B3 & 100.2 & 5.75 & 2 & 190 & 2 \\
\hline
\end{tabular}

Table 2. Formulations of castor oil based polyol

\begin{tabular}{ccccc}
\hline Sr. No. & $\begin{array}{c}\text { Castor Oil } \\
(\mathrm{gm})\end{array}$ & Acid (gm) & $\begin{array}{c}\text { Temperature } \\
\left({ }^{\circ} \mathrm{C}\right)\end{array}$ & Time (hrs) \\
\hline B1 with HCL & 46.6 & 36 & 60 & 1 \\
\hline B2 with Acetic Acid & 46.6 & 36 & 60 & 1 \\
\hline
\end{tabular}

at atmospheric pressure and solution was stirred by magnetic stirrer. Mixture obtained after cooling to room temperature was dissolved in $150 \mathrm{ml}$ of chloroform and re-crystallized overnight in refrigerator. Polyol precipitates were separated by filtration by watt man filter paper 41 followed by vacuum drying at vacuum of $0.2 \mathrm{Kg} / \mathrm{m}^{2}$ at $60{ }^{\circ} \mathrm{C}$ for $10 \mathrm{~min}$ in vacuum oven LVO-2040 Labtech Korea. Different batches were prepared in the same manner. Formulation which was used for the synthesis of soybean oil based polyol is given in table 1 and its detailed reaction is shown in figure 2 .

\section{Synthesis of castor oil based polyol}

Castor oil was taken in beaker and $5 \%$ solution of $\mathrm{HCl}$ for $1^{\text {st }}$ batch and acetic acid for $2^{\text {nd }}$ batch was added in it. The mixture was heated to $60{ }^{\circ} \mathrm{C}$ for time of $1 \mathrm{hr}$ followed by cooling to room temperature. Two layers were formed with lower layer of water and upper of polyol which were separated by using separating funnel. Formulation which was used for the synthesis of polyol is given in table 2 and its chemical reaction is shown in figure 3 .

\section{RESULTS AND DISCUSSIONS}

\section{Soybean and castor oil characterization}

\section{Saponification value, molecular weight and iodine value test}

Saponification number of soybean and castor oil was determined by the experimentation and its value was calculated by using the following formula (ASTM D464):

Saponification value $=($ Amount of $0.5 \mathrm{~N}$ $\mathrm{HCl}$ used in flask $\mathrm{A}$ - Amount of $0.5 \mathrm{~N} \mathrm{HCl}$ used for flask B) $\times 28$ / weight of the oil sample

Saponification value of soybean oil was recorded as 196 and this value for castor oil was found to be 175 . 

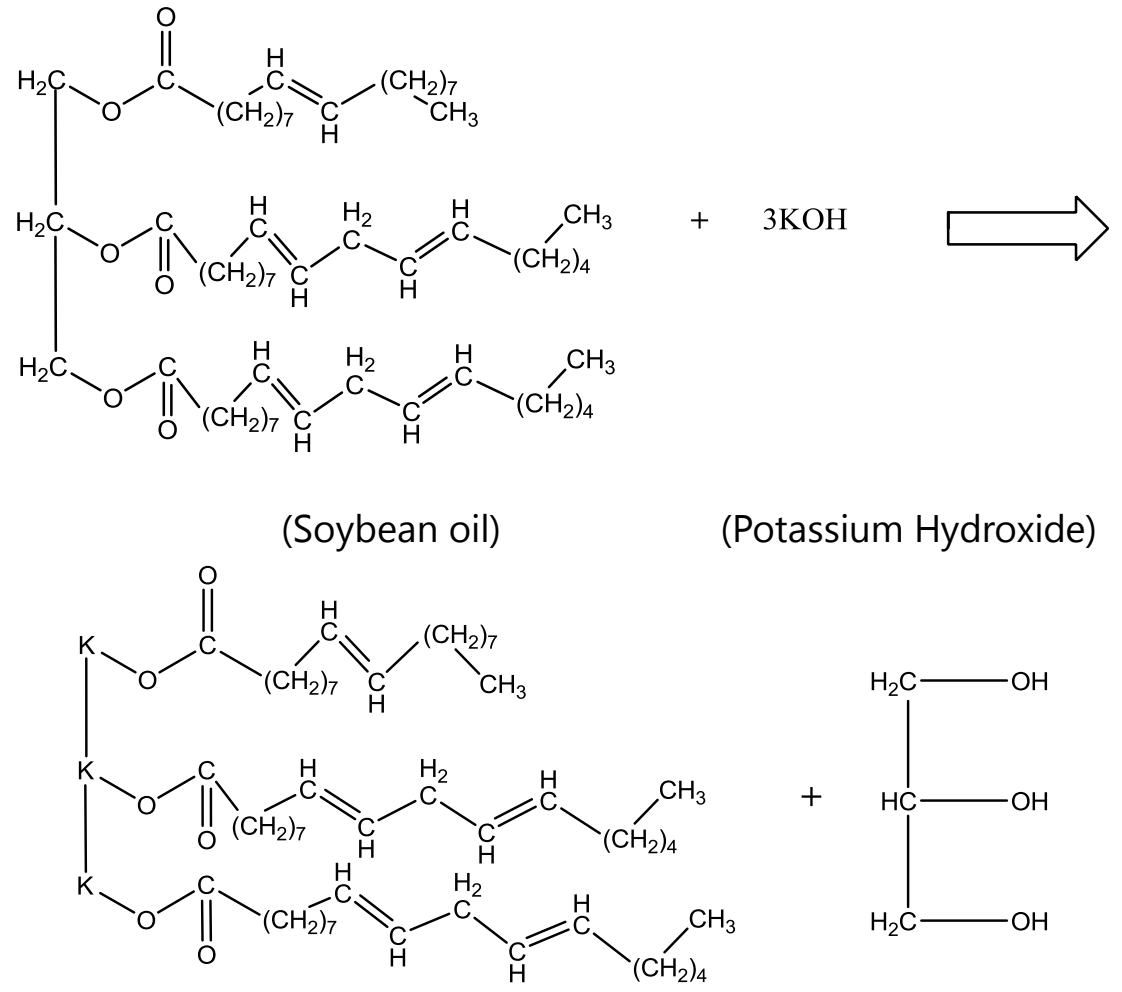

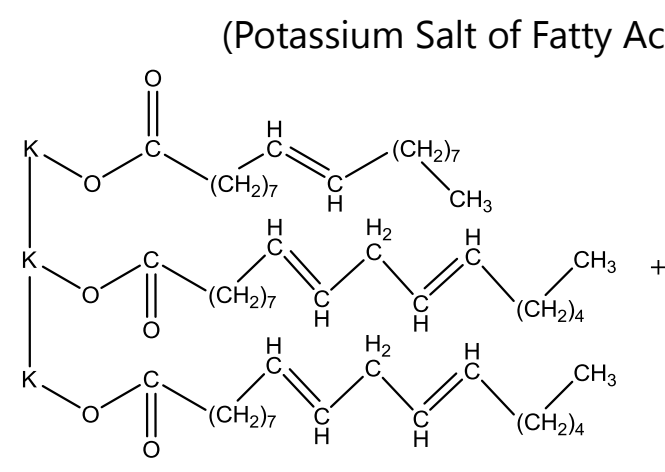

(Potassium Salt of Fatty Acid)
(Glycerol)

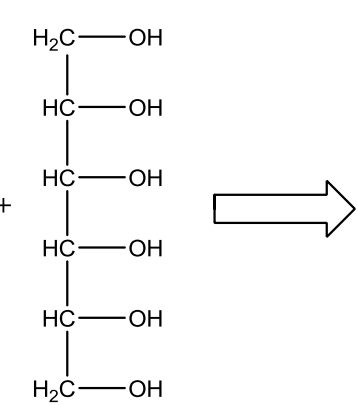

(Sorbitol)<smiles>CCC=CCC(=O)OC(COC(=O)C/C=C/C/C=C/CC)C(O)C(O)CO</smiles>

(Polyol)

(Potassium Hydroxide)

Fiq. 2: Schematics of polyol from soybean oil 
<smiles>CCC(O)C/C=C/CC(=O)OCC1COC(=O)C/C=C/CC(O)C(CC)C(CC)C1</smiles>

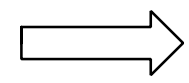

(Castor Oil)<smiles>CCC(Cl)CC=CCC(=O)OC1COC(=O)CC=CCC(Cl)(CC)CC1(Cl)CC=CCC(=O)OC</smiles>

(Polyol)

Fig. 3: Schematics of polyol from castor oil

Molecular weight was also determined for soybean oil and castor oil by a formula which is given as under (ASTM D464):

Molecular Weight of Fat $=168000 /$

Saponification Number of Oil

It was found to be $857 \mathrm{~kg} / \mathrm{kgmol}$ for soybean oil and for castor oil it was calculated as $960 \mathrm{~kg} / \mathrm{kg}$ mol.

From experiment the iodine value of soybean oil was determined and the formula which was used for its calculation is described as below (ASTM D5768-02):
Iodine value $=($ Amount of $0.1 \mathrm{~N}$

$\mathrm{Na}_{2} \mathrm{~S}_{2} \mathrm{O}_{3} .5 \mathrm{H}_{2} \mathrm{O}$ utilized for blank solution Amount of $0.1 \mathrm{~N} \mathrm{Na}_{2} \mathrm{~S}_{2} \mathrm{O}_{3} .5 \mathrm{H}_{2} \mathrm{O}$ utilized for solution containing oil) $\times 0.0127 \times 100$

This value was found to be 127 for soybean oil which show that soybean oil contains two double bonds and was recorded as 85 for castor oil. Castor oil is also known as non-drying oil because it has low iodine value (Hatice, 2010).

Table 3 shows the saponification number, molecular weight and iodine number of soybean oil and castor oil. 
Table 3. Characterization results of soybean and castor oil

\begin{tabular}{cccccc}
\hline Sr. No. & Oil & $\begin{array}{c}\text { Saponification } \\
\text { No. }\end{array}$ & $\begin{array}{c}\text { Molecular } \\
\text { Weight } \\
(\mathrm{kg} / \mathrm{kgmol})\end{array}$ & Iodine No. & $\begin{array}{c}\text { No. of } \\
\text { Double } \\
\text { Bonds }\end{array}$ \\
\hline 1 & Soybean Oil & 196 & 857 & 127 & 2 \\
\hline 2 & Castor Oil & 175 & 960 & 85 & - \\
\hline
\end{tabular}

Table 4. Acid values of castor and soybean oil based polyol

\begin{tabular}{cccc}
\hline Sr. No. & \multicolumn{2}{c}{ Sample code } & $\begin{array}{c}\text { Acid Value }(\mathrm{mg} \\
\mathrm{KOH} / \mathrm{gm})\end{array}$ \\
\hline \multirow{2}{*}{1} & $\begin{array}{c}\text { Castor oil based } \\
\text { polyol }\end{array}$ & B1 with HCL & 3.0 \\
\cline { 3 - 4 } & $\begin{array}{c}\text { Soybean based } \\
\text { based Polyols }\end{array}$ & B2 with Acetic Acid & 3.0 \\
\cline { 3 - 4 } & & B1 & 7.16 \\
\cline { 3 - 4 } & & B2 & 5.2 \\
\hline
\end{tabular}

\section{Polyol Characterization}

\section{Acid value test}

Test for acid value determination was conducted according to ASTM D 4662. According to which, conical flask of $250 \mathrm{ml}$ was taken and 5-10 gm of sample was added in it with $50 \mathrm{ml}$ of neutralized ethyl alcohol. Water bath was used to heat solution and it was titrated against $0.1 \mathrm{~N}$ $\mathrm{KOH}$ using phenolphthalein as an indicator till pink end point was obtained (El-Tayeb, 2008, Fei, 2008). Acid value was calculated by using the following formula (ASTM D4662):

Acid Value $=$ Vol. of $0.1 \mathrm{~N} \mathrm{KOH}$ consumed for sample $x$ Normality of $\mathrm{KOH} \times 56.1 / \mathrm{Wt}$. of the sample in gms

Acid value of polyol shows the presence of $\mathrm{OH}$ (hydroxyl) group and help to find which type of foam will be synthesized from polyol (soft or rigid) on reacting with isocyanate. Polyol with high acid value produces rigid foam and if the acid value is low then foam formed will be soft. For batch 1 the acid value is $7.16 \mathrm{mg} \mathrm{KOH} / \mathrm{gm}$ and the foam formed was rigid. For batch 2 and 3 the acid value is $5.2 \mathrm{mg} \mathrm{KOH} / \mathrm{gm}$ and $3.8 \mathrm{mg} \mathrm{KOH} / \mathrm{gm}$ respectively. The foam formed from batch 2 and 3 was softer than of batch 1 which reveals the fact of formation of soft foam by use of polyol of low acid value.

\section{Reaction of polyol with Methylene diphenyl diisocyanate (MDI)}

$10 \mathrm{ml}$ of synthesized polyol and $10 \mathrm{ml}$ MDI were mixed in a beaker at $30^{\circ} \mathrm{C}$. Three to four drops of water were added as blowing agent into the mixture. Polyurethane foam was formed after thirty minutes which is shown in figure 4 . It is a confirmatory test for the synthesis of polyol. 
Shahzad Maqsood Khan, Nafisa Gull, Muhammad Yaseen Akram, Hakim Ali Haider, 35 Muhammad Yasir Akram, Muhammad Imran, Muhammad Taqi Zahid Butt and Tahir Jamil

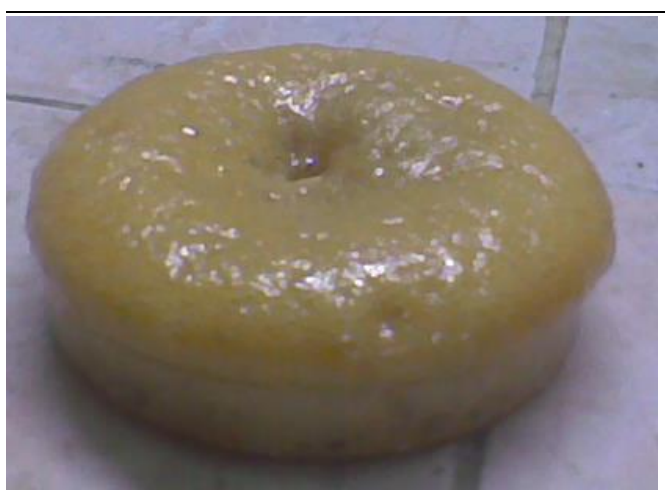

Fig. 4: Polyurethane from formation

\section{FTIR analysis}

In figure 5, spectra of soybean oil is labeled as "a". It shows the double bond peak $\mathrm{C}=\mathrm{O}$ group at $1743.65 \mathrm{~cm}^{-1}$ with peak area $5.207 \mathrm{~cm}^{2}$. Since two double bonds are presents in the soybean oil chain, so the polyol containing two hydroxyl groups can be synthesized. Figure 3, spectra "b", "c" and " $\mathrm{d}$ " are labeled for the soy based polyol batch 1,2 and 3 with acid value of $7.16 \mathrm{mg}$ $\mathrm{KOH} / \mathrm{g}$ of batch $1,5.2 \mathrm{mg} \mathrm{KOH} / \mathrm{g}$ of batch 2 and $3.8 \mathrm{mg} \mathrm{KOH} / \mathrm{g}$ of batch 3. Spectra "b" shows a broad band in the region 3398.57 $\mathrm{cm}^{-1}$ and peak area of $240.024 \mathrm{~cm}^{2}$ for batch 1 due to $-\mathrm{OH}$ (Hydroxyl) group formed by esterification and transesterification of Soybean Oil. Another peak around 1741.72 $\mathrm{cm}^{-1}$ with peak area $77.741 \mathrm{~cm}^{2}$ is also prominent which is due to $\mathrm{C}=\mathrm{O}$ group is for batch 1 . Spectra " $c$ " is labeled for batch 2 of soybean based polyol showing $-\mathrm{OH}$ (Hydroxyl) group peak at $3388.93 \mathrm{~cm}^{-1}$ with peak area of $174.616 \mathrm{~cm}^{2}$ and $C=0$ group peak at $1735.93 \mathrm{~cm}^{-1}$ with peak area 69.266 $\mathrm{cm}^{2}$. Spectra " $\mathrm{d}$ " which indicates batch 3 of soybean based polyol with -OH (Hydroxyl) group at $3419.79 \mathrm{~cm}^{-1}$ and peak area of $134.089 \mathrm{~cm}^{2}$ and $\mathrm{C}=\mathrm{O}$ group peak at $1739.79 \mathrm{~cm}^{-1}$ and peak area of $40.206 \mathrm{~cm}^{2}$.

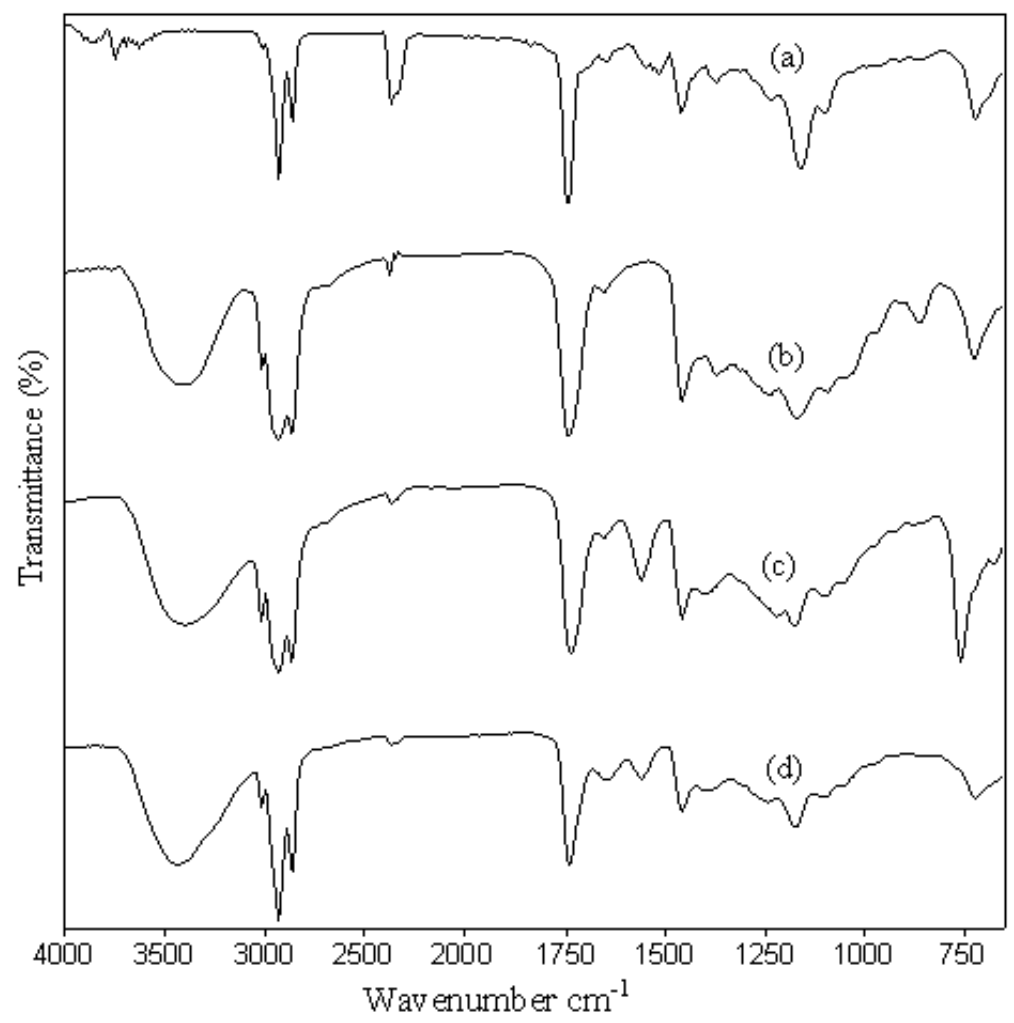

Fig. 5: Spectra of FTIR (a) Soybean Oil, (b) Soybean based Polyol Batch 1, (c) Soybean based Polyol Batch 2, (d) Soybean based Polyol Batch 3 


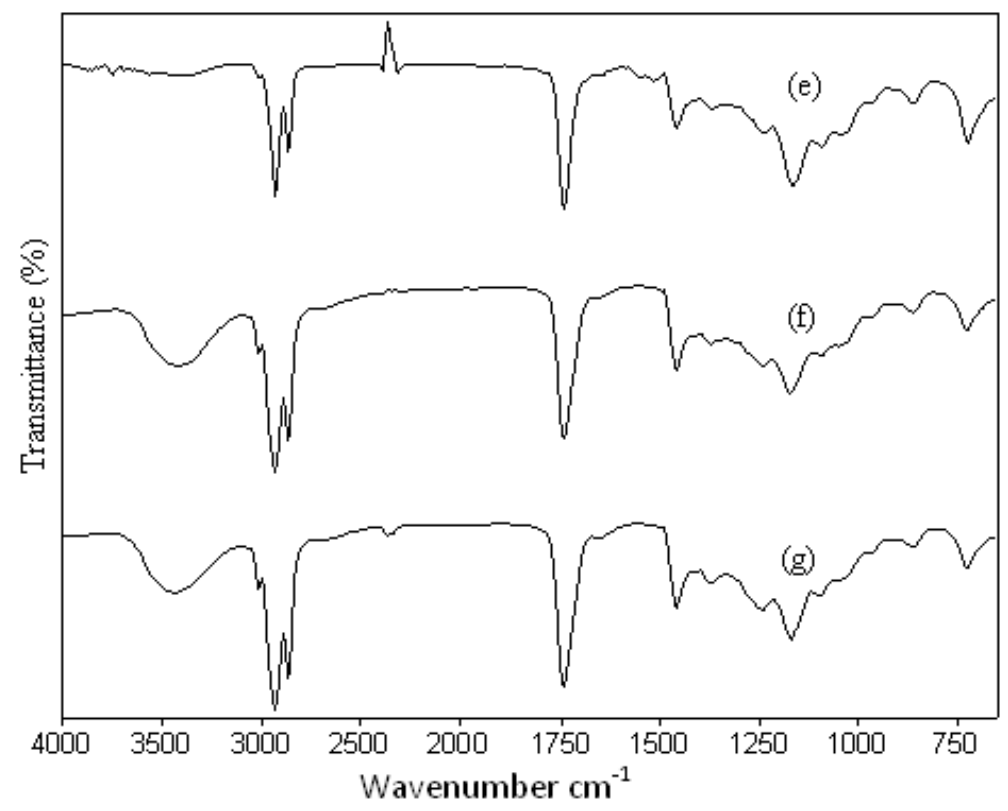

Fig. 6: FTIR spectra of (e) Castor Oil, (f) Castor Oil Base Polyol by $\mathrm{HCl}$, (g) Castor Oil Base Polyol by Acetic Acid

In figure 6, spectra " $e$ " illustrates for castor oil showing double bond peak of $\mathrm{C}=\mathrm{O}$ group at $3367.71 \mathrm{~cm}^{-1}$ with peak area $1.962 \mathrm{~cm}^{2}$ and peak of $-\mathrm{OH}$ group at $1741.72 \mathrm{~cm}^{-1}$ and area of peak is $5.722 \mathrm{~cm}^{2}$. Spectra " $f$ " and " $g$ " are labeled for castor oil based polyol with $\mathrm{HCl}$ and Acetic acid respectively with acid values of 3.0 each. Spectra "g" having a peak at $1741.72 \mathrm{~cm}^{-1}$ which is attributed to $\mathrm{C}=\mathrm{O}$ group with peak area $56.818 \mathrm{~cm}^{2}$ and at $3415.93 \mathrm{~cm}^{-1}$ of $-\mathrm{OH}$ (Hydroxyl) group having peak area of $170.601 \mathrm{~cm}^{2}$. Spectra " $h$ " is labeled for castor oil base polyol from Acetic Acid having peak at $1741.72 \mathrm{~cm}^{-1}$ of $\mathrm{C}=\mathrm{O}$ group with peak area $65.189 \mathrm{~cm}^{2}$ and at 3433.29 $\mathrm{cm}^{-1}$ of $-\mathrm{OH}$ (Hydroxyl) group with peak area of $173.864 \mathrm{~cm}^{2}$. These all peaks are in good favor of polyol formation.

\section{CONCLUSIONS}

In this study, commercial grade castor oil and soybean oil was employed for the synthesis of polyol. Both oils were analyzed by determining their saponification value, molecular weight and iodine value which showed that these oils are unsaturated and have double bonds. Synthesized polyol was analyzed by acid value test, polyurethane formation and FTIR analysis. Acid value results show the presence of $\mathrm{OH}$ (hydroxyl) group and also reveal that batch 1 is useful for the synthesis of rigid foam while batch 2 and 3 can be used for the production of soft type foam. FTIR spectra verify the absence of $\mathrm{OH}$ group in pure soybean oil and castor oil While confirm $\mathrm{OH}$ peak in oil based polyols also indicating the formation 
Shahzad Maqsood Khan, Nafisa Gull, Muhammad Yaseen Akram, Hakim Ali Haider, 37 Muhammad Yasir Akram, Muhammad Imran, Muhammad Taqi Zahid Butt and Tahir Jamil

of polyol as $\mathrm{OH}$ group is added in the soybean oil on reacting with sorbitol. Moreover, decrease in $\mathrm{OH}$ peak area also verifies the decrease in acid value.

\section{ACKNOWLEDGMENT}

We are thankful to Engr. Muhammad Shafiq; Department of Polymer Engineering and Technology, University of the Punjab, Lahore Pakistan for helping us in testing.

\section{REFERENCES}

1. ASTM D464 Standard Test Method for Determination Saponification Number of Naval Stores Products Including Tall Oil and Other Related Products.

2. ASTM D5768-02 Standard Test Method for Determination of Iodine Value of Tall Oil Fatty Acids.

3. ASTM D4662 Standard Test Method for Determination of Acid value.

4. ASHIDA, K. 2007. Polyurethane and Related Foams, Raton London Newyork, Taylor \& Francis.

5. BAYER, O. 1947a. Angewandte Chemie, A. 59.

6. BAYER, O. 1947b. Modern Plastics. 24.

7. DETROIT. 1998. Proceedings of an International Symposium on 60 Years of Polyurethanes. In, USA.

8. EL-TAYEB, N. S. M. 2008. A study on the potential of sugarcane fibers/polyester composite for tribological applications. Wear, 265, 223-235.

9. FEI, Y., ZHIPING, L., PAUL, C., YUHUAN, L., XIANGYANG, L., ROGER, R. 2008. Atmospheric Pressure Liquefaction of Dried Distillers Grains (DDG) and Making Polyurethane Foams from
Liquefied DDG. Appl. Biochem.

Biotechnol., 148, 235-243.

10. GUO, A., CHO, Y. J., PETROVIC, Z. S. 2000. Structure and properties of halogenated and nonhalogenated soybased polyols. J. Polym. Sci.: Part A: Polym. Chem., 38, 3900-3910.

11. GUO, A., DEMYDOV, D., ZHANG, W., PETROVIC, Z. S. 2002. Polyols and Polyurethanes from hydro formylation of soybean oil. J. Polym. Environ., 10, 4952.

12. HATICE, M., AND MICHAEL, A. R. M. 2010. Castor oil as a renewable resource for the chemical industry. European Journal od Lipid Science and Technology, $112,10-30$.

13. JHON, J., BHATTACHARYA, M., TURNER, R. B. 2002. Characterization of polyurethane foams from soybean oil. J. Appl. Polym. Sci., 86, 3097-3107.

14. KHOE, T., OTEY, F., FRANKEL, E. 1972. Rigid urethane foams from hydroxy urethylated linseed oil and polyol esters. J. Am. Oil. Chem. Soc., 49, 615618.

15. LONESCU, M. 2005. Chemistry and Technology of Polyols for Polyurethanes, Shawbury, Shrewsbury, Shropshire, SY4 4NR, United Kingdom, Rapra Technology Limited.

16. MAXIME, E., MYRIAM, D., REMI, A., SYLVAIN, C., BERNARD, B. 2012. From Vegetable Oils to Polyurethanes: Synthetic Routes to Polyols and Main Industrial Products. Polymer Reviews, 52, 38-79.

17. MIHAIL, I., ZORAN, S. P., XIANMEI, W. 2007. Ethoxylated Soybean Polyols for Polyurethanes. J. Polym. Environ., 15, 237-243. 
18. MYRIAM, D., SYLVAIN, C., VINCENT, L., REMI, A., BERNARD, B. 2011. Synthesis of Biobased Polyols by ThiolEne Coupling from Vegetable Oils. Macromolecules, 44, 2489-2500.

19. PHUONG, T., DANIEL, G., RAMANI, N. 2005. Ozone-Mediated Polyol Synthesis from Soybean Oil. J10972 in JAOCS, 82, 653-659.

20. SIMONE, C. G., MARCO, F. F., ANNELISE, E. G. 2007. Determination of the Hydroxyl Value of Soybean Polyol by Attenuated Total reflectance/Fourier Transform Infrared Spectroscopy. J. Amer. Oil. Chem. Soc., 84, 503-508.
21. STEFAN, O. 2010. Synthesis and Properties of Polyurethane Elastomers with Castor Oil as Crosslinker. J. Am. Oil. Chem. Soc., 87, 313-320.

22. SURESH, S. N., XIAOHUA, K., LAZIZ, B., PETER, S. 2007. Physical Properties of Polyurethanes Produced from Polyols from Seed Oils: II. Foams. J. Amer. Oil. Chem. Soc., 84, 65-72.

23. SZYCHER, M. 1999. Isocynate Chemistry, New York.

24. XIAOHUA, K., GUOGUANG, L., HONG, Q., JONATHAN, M. C. 2013. Preparation and characterization of high-solid polyurethane coating systems based on vegetable oil derived polyols. Progress in Organic Coatings, 76, 1151-1160. 